\title{
Parent Perspectives on the Presentation, Triggers, Impact, and Support of Anxiety in Young Children on the Autism Spectrum
}

Simpson, K., Adams, D., Wheeley, E., \& Keen, D.

\begin{abstract}
Objectives: A high proportion of children with autism experience elevated anxiety, which is evident from an early age. Although parents provide a significant role in recognising the early signs and triggers of their child's anxiety and in prompting help-seeking, there are few studies using qualitative methods to document parent perspectives around their child's anxiety. The aim of this study is to explore parent perspectives of their child's anxiety across home and school.
\end{abstract}

Methods: Semi-structured interviews were conducted with parents of 10 young children (5 -8 years) with autism to explore their understanding of their child's presentation and triggers of anxiety across different settings (home and school) as well as the strategies and supports used to manage the anxiety in the home and school setting. Thematic analysis of the data

Results: Parents reported signs of anxiety were evident in their child from a young age but recognising these signs and distinguishing anxiety from other behaviours was difficult. Triggers identified related to sensory experiences, academic expectations, social demands, and uncertainty, all of which were discussed in relation to the school context. Parents shared how supporting their child with autism is multifaceted and is related to understanding the individual child's anxiety.

Conclusions: These findings highlight the heterogeneity of anxiety presentation in children with autism and the challenge in differentiating anxiety from other behaviours both in home and school settings. 
Autism Spectrum Disorders is a complex, lifelong neurodevelopmental condition with a current prevalence rate of 1 in 59 individuals (Baio et al., 2018). Anxiety disorders are significantly more common among children with autism than typically developing children, affecting up to $40 \%$ of children with autism (van Steensel, Bögels, \& Perrin, 2011) with an even larger number showing sub-clinical levels of elevated anxiety (Vasa et al., 2013). Heightened anxiety appears early in life for children with autism, with children as young as 5 -6 years of age showing elevated anxiety symptomatology at home (Keen, Adams, Simpson, den Houting, \& Roberts, 2019) and in the school setting (Adams, Simpson, \& Keen, 2018).

Recognising anxiety in children with autism is important because anxiety is known to have a substantial impact on peer and family relationships and on school performance (Lyneham et al., 2013). However, complex interactions between anxiety and autism mean that accurate recognition of anxiety can be difficult and that diagnostic overshadowing is a real and potential risk (White, Oswald, Ollendick, \& Scahill, 2009). In addition, some researchers have proposed that children with autism experience both typical and atypical (e.g. unusual specific phobias, fear around sensory experiences) anxiety symptoms, further complicating the identification of anxiety in this population (Kerns \& Kendall, 2012). In a recently published study, Adams, Young, Simpson, and Keen (2019) found that parents reported a wide range of anxiety-related behaviours not traditionally measured on standardised anxiety assessments and that these behaviours could vary across settings. Thus, while early detection is critical to ensure children receive appropriate treatment, there is a risk that due to the issues described above, anxiety in children with autism may go undetected and untreated.

Parents can play a significant role in the early identification and treatment of anxiety in their child with autism. Children may not report their own anxiety or identify the need for help so it is generally left to adults in their life to do this, usually parents (Stanger \& Lewis, 
1993). Although parents have been the predominant respondent in studies exploring anxiety in children with autism (with only $25 \%$ of studies in van Steensel et al.'s [2011] systematic review including self-report data from children), the quantitative methodologies used have limited the extent to which the research has explored parental understanding and perceptions of anxiety in children with autism. The small, but growing, literature base of studies which have used qualitative methodologies (focus groups, open-answer questionnaires, and interviews) with parents and caregivers (Adams, Young, et al., 2019; Bearss et al., 2016; Ozsivadjian, Knott, \& Magiati, 2012) have provided important information around both the presentation and management of anxiety. Whilst these qualitative studies have tended to focus upon description and management, there remains little information around the impact of the child's anxiety, particularly relating to the school setting.

Although there is limited research exploring anxiety related to the school setting in children with autism (Adams, Young, \& Keen, 2019), it is widely accepted that the combination of the profile of autism with that of anxiety is likely to have a significant impact on the individual's educational experience and engagement (Ashburner, Ziviani, \& Rodger, 2010; Ferraioli \& Harris, 2011; Fujii et al., 2013). Anxiety relating to school may not only (or may not ever) present in the school setting, with some individuals on the autism spectrum reporting masking their difficulties during the day and having to manage them when they return home (Ozsivadjian et al., 2012). There is therefore a need to explore anxiety related to school from a range of perspectives, including that of the parent. This is particularly important for younger children, where self-report and/or recall of information from the past is suggested to be less reliable (for a review of child self-report measures in mental health, including reliability and validity, see Greco, Lambert, and Park, 2016)

The aim of this study was therefore to explore parental perceptions of their child's anxiety: its development, presentation, and impact in the home and school setting. Given the 
recent recognition of the elevated anxiety symptomatology in young children with autism (Keen et al., 2019) coupled with the recent reports of parent-mediated interventions with strong effect sizes for preventing and/or reducing anxiety in young children with autism (Bischof, Rapee, Hudry, \& Bayer, 2018), the focus of this study was on children aged $5-8$.

\section{Method}

Ethical clearance was granted by Griffith University human research ethics committee. All procedures performed were in accordance with the ethical standards of the institutional research committees and with the 1964 Helsinki declaration and its later amendments or comparable ethical standards.

\section{Participants}

Parents of children ( $5-8$ years) with autism received information about the study through local primary schools or social media posts. Parents who were interested were able to follow a link to the online information sheet and consent form. Those who provided consent were asked to complete an online survey about their child's anxiety and behaviour and to complete an interview with a member of the research team.

Ten parents who identified their child as experiencing anxiety participated in the study. Demographic information is provided in Table 1. Parents were mostly mothers $(90 \%)$, aged between 31 and 50 years, with the majority (80\%) reporting having post-secondary education. Two participants (Vanessa and Steve) were married and provided combined information on their child, and one participant (Anna) was a parent of two children on the spectrum within the target age range for the study ( $5-8$ years). Based on parent-completed questionnaires, all children scored above the autism screener cut-off on the Developmental Behaviour Checklist-Autism Screening Algorithm (Brereton, Tonge, Mackinnon, \& Einfeld, 2002), and were reported to have elevated levels of anxiety based on the ASC-ASD-P cut-off (Rodgers et al., n.d.). The proportion of males and females was 1:1, highlighting that there 
was a higher proportion of females within this sample than is representative based upon current prevalence figures (Loomes, Hull, \& Mandy, 2017). Children were all attending mainstream schools. Pseudonyms are used for parent and child names.

\section{Procedure}

Semi-structured interviews were conducted with participants by KS. The interviews all followed the same interview guide (available on request) designed to explore participants' perceptions of their child's experiences of anxiety. The interview guide included questions exploring (a) how parents recognise anxiety in their child, (b) parental perception of the presentation and triggers of the child's anxiety across home and school, and (c) ways in which their child's anxiety was managed in the home and school setting. Interviews ranged in length from 20 min to 53 min. Parents were provided with the option of conducting the interview face-to-face or using video conferencing. Four interviews were conducted face-toface in their home, and six interviews were conducted using video conferencing. All interviews were audio-recorded, and transcribed verbatim.

\section{Measures}

Measures were used to obtain descriptive data of the participants, and their child's autism and anxiety characteristics. This information was not used in the analysis.

Demographic characteristics. These were collected by a parent questionnaire focusing upon child (age, gender, age at diagnosis), parent (education, employment), and household (income) variables.

Autism characteristics. The Autism Screener (part of the Developmental Behaviour Checklist Primary Carer Version [DBC-P]; Einfeld \& Tonge, 1995) was used to provide secondary validation of the parent-reported diagnosis of autism. The internal consistency, inter-rater and test-retest reliability, and concurrent validity are stated to be satisfactory or above in children (Einfeld \& Tonge, 1995). 
Child anxiety symptomatology. The Anxiety Scale for Children with Autism Spectrum Disorder - Parent report (ASC-ASD-P; Rodgers et al., 2016) was used to validate the presence of anxiety symptomatology within the sample. This is a recently developed scale designed to assess symptoms of anxiety in children with autism. The ASC-ASD has 24 items, each measured on a 4-point scale ranging from never (0) to always (3), resulting in a maximum possible score of 72. Two indicative cut-off points for the ASC-ASD total scale have been put forward by the authors: Scores $\geq 20$ suggest "significant anxious symptomatology", and scores $>24$ are considered to be a "more specific indication of significant anxiety" (Rodgers et al., n.d.). The ASC-ASD has good discriminant validity (den Houting, Adams, Roberts, \& Keen, 2018a) and concurrent validity with the Spence Child Anxiety Scale (den Houting, Adams, Roberts, \& Keen, 2018b).

Table 1 goes about here

\section{Data Analysis}

Interview transcriptions were analysed using thematic analysis based on Braun and Clarke's $(2006,2012)$ six-step process. These steps are iterative and include the following: familiarising yourself with the data; generating initial codes; searching for themes; reviewing potential themes; defining and naming themes; and producing the report (Braun \& Clarke 2012).

Two researchers (KS, EW), one with expertise in autism studies and the other proficient in qualitative methods, read each interview transcript to become familiar with the data. One researcher (EW) then analysed the data line-by-line to generate initial codes that reflected discrete ideas the participants presented in response to the three core questions. Following this, the two researchers collaboratively devised guidelines for judgements about codes. The code information developed included definitions and any exclusions (MacQueen, McLellan-Lemal, Bartholow, \& Milstein, 2008). For example, anxiety response was 
described as a behaviour identified by the parent as anxiousness in response to a situation or stimulus. Throughout the analysis process, the two researchers worked together to verify codes and examine emerging themes. Data were stored and the analysis process documented using NVivo (QSR, 2015). The use of NVivo assisted in creating an audit trail (Creswell \& Miller, 2000) where data, codes, memos, and documentation of analysis procedures were developed and reviewed.

\section{Results}

Analyses of the interview transcripts yielded 10 themes that are presented in relation to the three key areas addressed in the parent interview: parents' identification of anxiety in their child (three themes), parental perception of the presentation and triggers of the child's anxiety across home and school (five themes), and support and strategies (two themes). These are summarised in Figure 1.

Figure 1 goes about here

\section{Parent's identification of anxiety in their child}

Parents felt they were able to identify when their child was anxious. Three themes related to identifying anxious behaviour were identified. They include: looking back, parents can identify early signs of their child's anxiety; detecting anxiety may be difficult; and differentiating between anxiety and other behaviours is complex.

\section{Looking back, parents can identify early signs of their child's anxiety. Upon} reflection, most parents were able to identify behaviours that indicated anxiousness in their child from an early age (under 3 years), although their insight into these as signs of anxiety at the time varied. These early signs included their child having difficulty sleeping when young, challenges when away from home and, as Vanessa described Harrison, "always a sort of a fearful, skittish, very scared easily child". Parents reported that signs became more obvious when their child commenced school; Paula said, "when she turned 4, or even started 
preschool, things just got a lot more challenging for her, a lot more overwhelming for her. So that period, between 4 and 5, was really, a really challenging year". Likewise, Anna described this as a period where things "fell apart", with Kahil's Prep year being an "absolute nightmare".

Detecting anxiety may be difficult. Recognising signs of anxiousness was viewed as initially difficult for parents, with Zita describing this as "just a vibe I had in my gut", and Deanne explaining, "So it's taken a while to figure out". Reflecting back, Anna felt she could now recognise some of Amelia's early behaviour as anxiety “even though Amelia really covered it very well because of her level of intelligence. But now knowing her mimicking and her roleplaying and that covered a lot".

Parents all described behaviours they now recognised as signs of their child's anxiety. These included sleeping problems, feeling sick, agitation, crying, or having a meltdown. In addition, avoiding and running away were frequently identified. Behaviours unique to each child were also reported. Raelene noted that Max "blocks his ears". Vanessa explained that Harrison would become agitated "not necessarily cry or melt down, but be on the verge", whereas Paula described Mia as becoming overwhelmed and this was evident as Mia "just upsets or hiding into me or screaming". Likewise, Anna described different behaviours in her two children. For example, Amelia's behaviour changed: "rather than being extraverted, she'll go introverted. She grinds her teeth if she's very anxious", whereas for Kahil, "talking louder is a huge indication that something's not quite right".

Although parents felt it had taken time to identify behaviours that indicated their child was anxious, they were all able to tell when their child was relaxed or not anxious.

Descriptions included "she is very loving and very pleasant" (Paula), "a really caring little thing” (Tess), "a very happy boy" (Raelene), "total sweetheart” (Jessica), and a "cuddly and happy kid" (Kate). 


\section{Differentiating between anxiety and other behaviours is complex. Detecting}

anxious behaviour in their child has taken parents some time and is made complex by the need to understand what is typical behaviour for their child with autism and how anxiety manifests in their child. As Anna explained, "it is difficult to distinguish between what behaviour was viewed as typical for young children and what was anxiety". Recognising differences in their child's typical behaviour was identified as a way of detecting anxiety. Parents discussed their views about the relationship between anxiousness and autism and the differences between anxious behaviours, autism behaviours, and other behaviours that challenge, not perceived to be related to their autism or anxiousness,

In particular, parents noticed that when their child was anxious there was an exacerbation in their autism characteristics, in particular, behaviours related to the restricted and repetitive domain. Vanessa and Steve commented on how anxiety impacted on Harrison's restricted interests: “when his anxiety is heightened, he really obsesses more with those obsessions". Similarly, Jessica observed a relationship between Layla's anxiety and her repetitive movements: "When she's anxious, the behaviours [stimming] come out ... [and] when she's not anxious, she tends not to do that stuff...". The relationship between anxiety and autism behaviours was viewed by Paula as highly related:

I don't think we can separate the insistence on the same and the anxiety as such.

Because I think that when things change, that provokes anxiety for her. So I think that they're highly related. So I think when she's already anxious for other reasons, she's even less flexible.

In contrast, Kate perceived autism and anxiety differentially impacted on Blake's ability to move between tasks. She attributed Blake's behaviour to autism when "I think he gets fixated on something, and until he's finished it, he can't disengage from that thought and move on". In contrast, when he was anxious, Blake was “worried about what's coming next". 
Distinguishing anxious behaviour from other behaviours came down to parents' knowledge of their child and making personal judgements. Zita pointed out that it was not always easy to distinguish between anxious behaviours and other behaviours that challenge and it often came down to "personal judgement on what you're trying to get him to do. Then you kind of know whether it's anxiety or is it because he just is being a bit lazy". Other parents provided similar examples of making judgements about differences between anxiety and other behaviours. Raelene based her judgement on the extent to which Max would listen to her. When he was anxious "he just says "leave me alone ... go away", whereas with other behaviours "you explain to him and talk to him and ... he does listen". Tess identified that Georgia would respond quite differently when "anxious angry" than when angry. ... her anger with [challenging] behaviour will be her trying to get her way. It's her way or the highway. But, anger with anxiety is, her body reacts as well. Like she'll get bright red, her eyes will water and she clenches her hands ... she looks at you and ... you can see ... the fear in her. Similar distinctions were made by Deanne, who remarked that when Rebecca was anxious she was more likely to complain of feeling sick, but when she was attention seeking she verbalised a need. Personal judgements were also made based on what was viewed by the parent as typical child behaviour. Jessica viewed sibling fighting as "just being really a kid" rather than related to anxiety.

Some parents felt that all their child's behaviours that challenge were somehow linked to anxiety. For example, Kate felt there:

was little behaviour that was him genuinely saying, "Right, I know you want this but I'm going to do something else". ... It's just the, “I'm stressed about this and I'm digging my heels in." 


\section{Parental perception of the presentation and triggers of the child's anxiety across home and school}

Parents identified five themes in relation to their perception of their child's presentation and triggers of anxiety at home and school. They were: children's anxiety about school can sometimes present at home; anxiety can be triggered by sensory challenges; academic performance can be associated with anxiety; the school context can also present with social challenges; and uncertainty of change across any setting can trigger anxiety.

Children's anxiety about school can sometimes present at home. The parents all identified school as a challenging context for their child, although the ways in which this presented differed across children. Tess, Deanne, and Jessica reported their child's anxiousness about school was noticeable by their difficulty sleeping the night before school. For Deanne this continued with the "school battle" around not wanting to go to school and Rebecca's behaviour at school.

She'll be very clingy at drop offs, and then as soon as you pick up she'll look miserable ... she'll say what was wrong with her that day. I went to the sick bay because I had a headache, I went to the sick bay because I had a sore leg, I had a - but then she'll be fine once you get home.

Raelene commented that sometimes Max "has the same meltdowns at school". In contrast, other parents (Anna, Zita, Paula, and Vanessa) described their child as "holding it together" at school and then acting out when they came home, with Anna depicting Kahil as "one of those champagne kids that come home and just let it all out".

Anxiety can be triggered by sensory challenges. Children's response to a range of different sensory information was identified as a factor that exacerbated anxiousness by parents of six children. Anna identified a range of sensory triggers for Kahil: "It could be something itching him. It could be a smell. It could be even a texture in his mouth. It could 
even be, you know, the place or the space that we're in that could increase it. It could even be past experiences as well”. Noisy environments were frequently identified as triggers by parents: "she knows that's going to be noisy, so she gets anxious about having to go to PE" (Jessica); Vanessa said that Harrison "does not go and do the playground up onto the oval, because it's too noisy. He can't handle the noise". Anna felt sensory issues had a huge impact on Amelia's anxiety as she would have difficulty concentrating and would not be working at her best.

Academic performance can be associated with anxiety. According to six parents, their child's anxiousness at school can be triggered by having to perform, with different tasks creating anxiety for different children. Anna related how Kahil became frustrated at school because he knew the spelling words but couldn't get them right on a test. This resulted in Kahil continually getting the same spelling words for homework. For Raelene, difficulty doing a task was something she felt increased her son's anxiety.

Several parents attributed their child's anxiousness with schoolwork to their perfectionism. Jessica mentioned, "I suspect that part of that [anxiety/behaviour] is tied up in how she feels about not doing something perfectly, getting it right"; Anna identified Kahil's "levels of frustration and his perfectionism". This carried over to homework, with Anna providing an example of how Amelia would continually rub out and rewrite her homework. “'Oh no, I need to make it neater.' So she rubbed it out and she rewrote it and then she rewrote it again".

According to the parents, their child's perception of themselves not performing well impacted on their anxiety. Tess discussed her daughter's worries about school in terms of failure in class and how Georgia had said "I hate school, I don't want to go to school, I only ever get Fs, I'm not good at school". In contrast, Deanne explained how teasing from other children had impacted on her daughter's self-perception in Grade 1: "she was starting to call 
herself stupid. ... Basically, some kids had teased her over her writing and stuff like that. I was dealing with her behaviour being off the charts".

Zita described how anxiousness would impact on her son's learning.

... at school he might be worrying about something that's happened in the playground and then ... he might not be focusing on the lesson and then he will miss it all and then he'll come home and he'll try and do his homework and then he doesn't know how to ... It does affect [his learning] when he's anxious.

The school context can also present with social challenges. Parents of five children identified socialising with other children as a trigger for anxiety as their child had difficulty understanding the behaviours of others. Kate explained, "I think he finds people very challenging, particularly new people because they are unpredictable because he can't see what's going to happen. I think he finds children his own age quite unpredictable.” Deanne saw this as impacting on friendships, "She was just really struggling on the friendship side", with Tess and Anna discussing their daughters' worries about whom to play with. Difficulties understanding social cues also impacted on the child's relationship with their teachers, resulting in "level of misunderstanding and then that level of fear. I don't want to get in trouble at school" (Anna - Kahil).

Uncertainty of change across any setting can trigger anxiety. Change was also identified as a potential contributor to anxiety, with Anna reporting that trying something new was huge for Kahil. Even the possibility of future change was identified as causing anxiety. Zita recounted how Noah would worry about whom his teacher would be the following year, and this impacted on his last term at school: "normally the last term he will, there'll be a lot of struggle at school”. Deanne recounted:

So then coming to Year 2, within a few weeks she had to change her position in her desk, she gets to school, and we got there a bit late, the only position left in the room 
was the furthest from the teacher possible and she lost it. And that day, and then in that thing, so it was because she wants to sit next to the teacher.

Anna reported:

We had for three days straight, I don't want to go to school, I don't want to go to school, I don't want to go to school. ... She found out one of the girls she was starting to connect to is leaving school next term.

\section{Supports and Strategies}

Parents were asked about the types of supports provided for their child and the strategies employed to manage anxiety. Two themes emerged from the interviews: supporting their child with autism and anxiety is multifaceted, and teacher support is related to understanding the individual child's anxiety.

Supporting their child with autism and anxiety is multifaceted. Although parents conveyed that they could identify whether or not a behaviour was a response to anxiousness, identifying ways to support their child could still be problematic. Anna reinforced that it could be challenging to identify the reason for a behaviour. She said, "You just have to take a stab in the dark and hope for the best, that you've got the right situation and the right solution". Furthermore, the support role parents performed was multifaceted as at times they provided direct counselling and strategies and other times acted as an advocate for their child.

Several parents indicated they found it useful to talk to their child about situations that made them anxious and their responses to these situations. According to Raelene, this helped Max plan an appropriate response. In addition, Anna had developed a process with her children to ask for what they needed: "I've deliberately taught them that because in a situation where they're really anxious and they don't know how to react, something short and sweet with respect to a command or a response works really well for my kids". Anxiety 
conversations were something that parents had developed over time. Paula explained how Mia could regulate her anxiety through discussing it with her:

She'll explain her anxiety to me. She asks for help. She can use more words rather than just behavioural responses to anxiety or overwhelm. She's able to talk about the things that do make her upset or do make her worry more. And she's willing to give more things a go in this past couple of months.

Further to communicating with their child, parents supported their children in a range of ways including modelling behaviours, reducing demands, "we reduced demands, offered a lot more choices, and saw a reduction in a lot of the behaviours" (Deanne), teaching relaxation skills, teaching their child to find a comfortable space, and providing their child with headphones.

Parents also perceived a role in advocating for their child, although they frequently found this to be challenging. Anna discussed that as a parent it was difficult to explain your child's anxiety to a third party: "it's socially and emotionally difficult to explain that to a third party that only has a vested interest so much". In addition, parents felt they were judged as an "overbearing helicopter parent that the school doesn't want to necessarily deal with" (Anna), "pedantic" (Deanne), and "not believed" (Paula).

Teacher support can be related to understanding the individual child's anxiety. Parents reported that teachers' awareness of their children's anxiety responses varied. Raelene commented that teachers who knew Max were more able to identify when he was starting to feel anxious: "Yeah, especially those [teachers] who have worked with him for a while they can see that he's getting anxious about something". Kate highlighted, in particular, "the special education staff at our school are amazing ... the classroom has been a bit hit and miss, but the special education staff are terrific". According to the parents, there were times 
when they felt the teachers misunderstood their child's behaviour. For example, Paula commented that teachers viewed Mia as shy while she saw this as anxiousness.

When teachers were aware of the child's anxiety, parents felt they were able to address this. Teachers used a range of approaches, with Jessica and Raelene both explaining that when teachers observed their child's anxiety building, they would ask the child if they wanted to take a break. Deanne shared how when Rebecca said "I feel sick, I've got a headache", the teacher would ask Rebecca "is there something else worrying you?" This led to Rebecca explaining she was worried about what other children were going to say about her work. Accommodations at break time were also reported by a number of parents, with children visiting the special education units during these times.

... first break he would just stand on the cement and just be with no-one, doing nothing, and tell his teacher that he was settling in and second break he does still go off to the support teacher, so it's with other children like himself, where he can just have quiet time. (Vanessa)

Zita explained how at the beginning of every year Noah would try the playground, but "then he'll see it doesn't work and then he'll go back to going to the SEP all the time. Normally that's where he is. First break and second break".

Where the school context was viewed as challenging and support was perceived to be inadequate, parents took a number of actions. Paula chose to homeschool, as "at this point in time, I don't think that she would cope in that, in a school environment at all”, whereas Deanne chose to change schools for Rebecca after recommended strategies from the psychologist and occupational therapist were not being implemented and support was not being provided. This contrasted with her experience at the new school where the teacher "almost instantly replied, I'm sending you straight to the guidance officer, this, this, this and 
this concerns me, we will be checking in on it, and already had a plan”. The school move has been very positive, with Deanne describing Rebecca as "Like she's a different kid".

\section{Discussion}

The aim of this study was to explore parental perceptions of the development, presentation, and impact of their child's anxiety in the home and school setting. Through the use of interview methodology, this study adds to the small but growing qualitative literature base around anxiety and autism. Although relatively small in number in comparison to quantitative studies in the area, when combined, the qualitative studies have yielded rich descriptions of the triggers, presentation, and support of anxiety in children with autism. This study builds upon the previous literature by being the first to focus upon young children (aged $5-8)$ on the autism spectrum experiencing anxiety. The three main themes - parents' identification of anxiety in their child, parental perception of the presentation and triggers of the child's anxiety across home and school, and support and strategies - are consistent with previous studies. This suggests that these areas are important to parents, across childhood, into adolescence, and possibly into adulthood, with similar themes emerging in the qualitative self-report studies with adults (e.g., Robertson et al., 2018).

When asked to reflect back, all parents were able to report behavioural indicators of anxiety in their children at a young age, although these indicators were not identified by parents at the time. Although the majority of anxiety research in children with autism focuses upon children aged 8 and above, there is recent research suggesting that signs of anxiety may be present in children as young as 5 (Keen et al., 2019). Within the typically developing literature, specific presentations (behavioural inhibition and shyness) have been identified as stable predictors of anxiety in adolescence (Chronis-Tuscano et al., 2009), suggesting that parent identification of precursors or earlier indicators of anxiety in children is possible and potentially clinically useful. However, a large, longitudinal study (Shephard et al., 2018) was 
unsuccessful in identifying any direct or significant predictors of anxiety in children with autism, concluding that early markers of anxiety and autism are difficult to differentiate early in life. Given the discussions around typical (i.e. DSM-consistent) and atypical (i.e. autismspecific) anxiety in children with autism (see Kerns \& Kendall, 2012), future studies may need to consider different predictors than those reported in the typically developing population, and these may need to be firstly informed by retrospective parent- or self-report studies.

Difficulty in differentiating autism from anxiety was discussed by parents within the interviews in this study, with parents reporting that such differentiation became easier over time. This is somewhat unsurprising as, post diagnosis, parents often have to go from having little knowledge of autism to specifically understanding how autism impacts upon their child, often with less than satisfactory post-diagnostic support (Crane, Chester, Goddard, Henry, \& Hill, 2016). Once parents develop an understanding of autism for their child, it increases the possibility of their being able to identify the potential impact of a variable co-morbid factor such as anxiety. The years of observing, trialling, and learning about their child's autism and anxiety results in parents (and their children) being rich sources of knowledge around the specific presentation and triggers of anxiety for their child, or what Adams, Clark, and Simpson (2019) refers to as a child's "anxiety signature". As parents within this study were all quickly and easily able to describe their child when no anxiety was present, it may be that alongside an "anxiety signature", it is also useful for parents to share markers of when a child is relaxed or not anxious. This may then help those who do not know the child so well to identify when the child is more or less anxious and adjust demands or implement appropriate supports or strategies. The potential benefit of teachers knowing and/or understanding the child's anxiety was identified by parents within the Supports and Strategies category, where parents noted the positive impact of teachers who understood their child and their child's 
anxiety and how it may impact upon their behaviour. This is important as signs of anxiety identified in this study e.g. avoiding and running away, may be misinterpreted as disruptive behaviour. Further research focussing upon anxiety, specifically within the school setting, is needed in order to support and enable teachers to feel confident in making informed decisions about what are age-appropriate or autism-related behaviours and what are normal variations of behaviour and/or mental health within the context of autism (Adams, MacDonald, \& Keen, 2019; Kerns \& Kendall, 2012; Wood \& Gadow, 2010). This will then enable them to identify their students' signs of anxiety and consequently, implement evidence-based classroom strategies to support and/or reduce the anxiety. This is particularly important given children with autism, even at a young age, show low participation rates at school (Simpson, Keen, Adams, Alston-Knox, \& Roberts, 2018).

The triggers identified by parents within this study align with those reported by parents of older children ( 7 - 18 years; Ozsivadijan et al., 2012) and adults (19 - 60 years; Roberston et al., 2018), suggesting that sensory challenges, academic or performance demands, social scenarios, and uncertainty are significant triggers for anxiety across age groups in multiple studies conducted across the world. Discussed in the review by South and Rodgers (2017), sensory profiles, social difficulties, and difficulties in tolerating uncertainty have also been identified as factors associated with anxiety within quantitative parent-report and self-report studies (e.g., Neil, Olsson, \& Pellicano, 2016; Uljarevic, Lane, Kelly, \& Leekham, 2016), with some studies beginning to explore the overlap between these factors and anxiety (e.g., Wigham, Rodgers, South, McConachie, \& Freeston, 2015).

Within this study, parents often drew upon their child's schooling experience in order to illustrate these triggers; for example, Jessica knowing that PE will be noisy, therefore increasing her anxiety, or Vanessa describing how Harrison does not go to the oval during playtime due to the noise. Parents spoke about how they feel that their child's anxiety can 
impact upon school attendance, participation, and academic performance. This finding is reflected in the literature; for example, a large-scale educational needs analysis placed anxiety within the top three factors affecting school participation and the top two factors influencing classroom support needs for children with autism (Saggers et al., 2016). The behavioural, rather than physiological, presentation of anxiety as behaviour is one that is being repeatedly reported in the recent anxiety and autism literature, but given the time lag between research and impact upon practice (see commentary about the research-to-practice gap specifically within the area of school mental health by Hoover, 2018), it is understandable that such findings have not yet influenced the perception of behaviours that challenge in the classroom. This highlights the need for easy-to-access and research-informed professional development materials for teachers and educators of children with a diagnosis of autism.

\section{Limitations and Future Diretions}

This study should be considered within the context of its limitations. As with many interview studies, the sample size is modest, from a relatively small geographical area, and only reflects the views of the participants who opted in to the study. There may have been a recruitment bias in those who participated and were able to give often several hours of their time to conduct the research without any incentive. Because the study was advertised through schools and the research centre's social media page, there may have been a bias towards parents whose children were particularly impacted by their anxiety in the school setting. Half of the children in this study were female, which is disproportionate to the current suggested gender ratio (Loomes et al., 2017) and therefore this may impact upon the generalisability of the findings. The extent to which gender impacts the presentation or severity of anxiety in children with autism is currently unclear, with studies reporting inconsistent findings (Magiati et al., 2015; Mandy et al., 2012). The limits to which parents are able to accurately 
describe their child's anxiety at school are also acknowledged, highlighting the need to repeat this study with teachers (and children) as co-informants.

Another limitation of this study was the lack of detailed information about the IQ or adaptive skills of the children involved and no gold-standard assessment of autism diagnosis, all of which were outside the scope of this study. All children within this study were attending mainstream schools, so generalising to children attending special schools should be tentative. Further research into the presentation, triggers, and impact of autism and anxiety in children with intellectual and developmental disabilities is needed, as this is an underresearched area (Adams \& Oliver, 2011; Flynn et al., 2017).

The difficulties in identifying anxiety in children with autism and distinguishing this from other behaviours highlighted the role of strong home-school communication to increase the potential for educators to identify anxiety-related behaviours (that may be idiosyncratic to individual children) and implement effective supports. Further research is required to understand anxiety presentation in young children with autism and how anxiety-related behaviours may impact on family and class dynamics and functioning.

\section{Conflict of interest}

The authors declare that they have no conflict of interest

\section{Ethical Approval}

All procedures performed in studies involving human participants were in accordance with ethical standards of the National Statement on Ethical Conduct in Human Research. This study was approved by the Griffith University Human Research Ethics Committee.

\section{Informed consent}

Informed consent was obtained from all participants

\section{Author Contributions}

KS: designed and executed the study, collected the data, assisted with the data analyses, and 
wrote the paper. DA: collaborated with the design and writing of the study. EW: analysed the data and wrote part of the results. DK: collaborated with the design and writing of the study. 


\section{References}

Adams, D. \& Oliver, C. (2011) The expression and assessment of emotions and internal states in individuals with severe or profound intellectual disabilities. Clinical Psychology Review, 31, 293-306. doi: 10.1016/j.cpr.2011.01.003

Adams, D., Clark, M., \& Simpson, K. (2019). The relationship between child anxiety and the quality of life of children, and parents of children, on the autism spectrum. Journal of Autism and Developmental Disorders. Advance online publication.doi:

10.1007/2Fs10803-019-03932-2

Adams, D., MacDonald, L., \& Keen, D. (2019). Teacher responses to anxiety-related behaviours in students on the autism spectrum. Research in Developmental Disabilities, 86, 11-19. doi: 10.1016/j.ridd.2018.12.009

Adams, D., Simpson, K., \& Keen, D. (2018). School-related anxiety symptomatology in a community sample of primary-school-aged children on the autism spectrum. Journal of School Psychology. 70, 64-73. doi: 10.1016/j.jsp.2018.07.003

Adams, D., Young, K., \& Keen, D. (2019). Anxiety in children with autism at school: A systematic review. Review Journal of Autism and Developmental Disorders, 1-15. doi: 10.1007/s40489-019-00172-z

Adams, D., Young, K., Simpson, K., \& Keen, D. (2019). Parent descriptions of the presentation and management of anxiousness in children on the autism spectrum. Autism. 23, 980-992. doi:10.1177/1362361318794031

Ashburner, J., Ziviani, J., \& Rodger, S. (2010). Surviving in the mainstream: Capacity of children with autism spectrum disorders to perform academically and regulate their emotions and behavior at school. Research in Autism Spectrum Disorders, 4, 18-27. doi:10.1016/j.rasd.2009.07.002 
Bearss, K., Taylor, C. A., Aman, M. G., Whittemore, R., Lecavalier, L., Miller, J., . . . Scahill, L. (2016). Using qualitative methods to guide scale development for anxiety in youth with autism spectrum disorder. Autism, 20, 663-672. doi: $10.1177 / 1362361315601012$

Bischof, N., Rapee, R. M., Hudry, K., \& Bayer, J. (2018). Acceptability and caregiverreported outcomes for young children with autism spectrum disorder whose parents attended a preventative population-based intervention for anxiety: A pilot study. Autism Research. doi:10.1002/aur.1963

Braun, V., \& Clarke, V. (2006). Using thematic analysis in psychology. Qualitative Research in Psychology, 3, 77-101. doi:10.1191/1478088706qp063oa

Braun, V., \& Clarke, V. (2012). Thematic analysis. In H. Cooper (Ed.), The handbook of research methods in psychology (pp. 57-71). Washington, DC: American Psychological Association.

Brereton, A. V., Tonge, B. J., Mackinnon, A. J., \& Einfeld, S. L. (2002). Screening young people for autism with the Developmental Behavior Checklist. Journal of the American Academy of Child \& Adolescent Psychiatry, 41, 1369-1375. doi:10.1097/00004583-200211000-00019

Baio, J., Wiggins, L., Christensen, D. L., Maenner, M. J., Daniels, J., Warren, Z., ... \& Durkin, M. S. (2018). Prevalence of autism spectrum disorders among children aged 8 years - autism and developmental disabilities monitoring network, 11 sites, United States, 2014. Morbidity and Mortality Weekly Report Surveillance Summaries, 67, 123. doi: $10.15585 / \mathrm{mmwr} . s s 6706 \mathrm{a} 1$

Chronis-Tuscano, A., Degnan, K. A., Pine, D. S., Perez-Edgar, K., Henderson, H. A., Diaz, Y., ... Fox, N. A. (2009). Stable early maternal report of behavioral inhibition predicts lifetime social anxiety disorder in adolescence. Journal of the American 
Academy of Child and Adolescent Psychiatry, 48, 928-935.

doi:10.1097/CHI.0b013e3181ae09df

Crane, L., Chester, J., Goddard, L., Henry, L., \& Hill, E. (2016). Experiences of autism diagnosis: A survey of over 1000 parents in the United Kingdom. Autism, 20, 153162. doi: $10.1177 / 1362361315573636$

Creswell, J. W., \& Miller, D. L. (2000). Determining validity in qualitative inquiry. Theory into Practice, 39, 124-130. doi: 10.1207/s15430421tip3903_2

den Houting, J., Adams, D., Roberts, J., \& Keen, D. (2018a). Exploring anxiety symptomatology in school-aged autistic children using an autism-specific assessment. Research in Autism Spectrum Disorders, 50, 73-82. doi: 10.1016/j.rasd.2018.03.005

den Houting, J., Adams, D., Roberts, J., \& Keen, D. (2018b). An exploration of autismspecific and non-autism-specific measures of anxiety symptomatology in school-aged autistic children. Clinical Psychologist. doi: 10.1111/cp.12174

Einfeld, S. L., \& Tonge, B. J. (1995). The Developmental Behavior Checklist: The development and validation of an instrument to assess behavioral and emotional disturbance in children and adolescents with mental retardation. Journal of Autism and Developmental Disorders, 25, 81-104. doi:10.1007/BF02178498

Ferraioli, S. J., \& Harris, S. L. (2011). Effective educational inclusion of students on the autism spectrum. Journal of Contemporary Psychotherapy, 41(1), 19-28. doi:10.1007/s10879-010-9156-y

Flynn, S., Vereenooghe, L., Hastings, R., Adams, D., Cooper, S-A., Gore, N., . . Waite, J. (2017). Measurement tools for mental health problems and mental well-being in people with severe or profound intellectual disabilities: A systematic review. Clinical Psychology Review, 57, 32-44. doi:10.1016/j.cpr.2017.08.006 
Fujii, C., Renno, P., McLeod, B. D., Lin, C. E., Decker, K., Zielinski, K., \& Wood, J. J. (2013). Intensive cognitive behavioral therapy for anxiety disorders in school-aged children with autism: A preliminary comparison with treatment-as-usual. School Mental Health, 5, 25-37. doi:10.1007/s12310-012-9090-0

Greco, V., Lambert, H. C., \& Park, M. (2016). Capturing the child's perspective: A review of self-report measures used with children. Occupational Therapy in Mental Health, 32, 228-244. doi:10.1080/0164212X.2016.1164104

Hoover, S. (2018). When we know better, we don't always do better: Facilitating the research to practice and policy gap in school mental health. School Mental Health, 10, 190198. doi:10.1007/s12310-018-9271-6

Keen, D., Adams, D., Simpson, K., den Houting, J., \& Roberts, J. (2019). Anxiety-related symptomatology in young children on the autism spectrum. Autism, 23, 350-358. doi:10.1177/1362361317734692

Kerns, C., \& Kendall, P. (2012). The presentation and classification of anxiety in autism spectrum disorder. Clinical Psychology: Science and Practice, 19, 323-347. doi:10.1111/cpsp.12009

Loomes, R., Hull, L., \& Mandy, W. P. L. (2017). What is the male-to-female ratio in autism spectrum disorder? A systematic review and meta-analysis. Journal of the American Academy of Child \& Adolescent Psychiatry, 56, 466-474. doi:10.1016/j.jaac.2017.03.013.

Lyneham, H. J., Sburlati, E. S., Abbott, M. J., Rapee, R. M., Hudson, J. L., Tolin, D. F., \& Carlson, S. E. (2013). Psychometric properties of the Child Anxiety Life Interference Scale (CALIS). Journal of Anxiety Disorders, 27, 711-719.

doi:10.1016/j.janxdis.2013.09.008 
MacQueen, K., McLellan-Lemal, M. E., Barthholow, K., \& Milstein, B. (2008). Team-based codebook development: Structure, process, and agreement. In G. Guest \& K. M. MacQueen (Eds.), Handbook for team-based qualitative research (pp. 119-135). New York: Rowman Altamira.

Magiati, I., Ong, C., Lim, X., Tan, J., Ong, A., Patrycia, F., . . Howlin, P. (2015). Anxiety symptoms in young people with autism spectrum disorder attending special schools: Association with gender, adaptive functioning and autism symptomatology. Autism, 20, 306-320. doi:10.1177/1362361315577519

Mandy, W., Chilvers, R., Chowdhury, U., Salter, G., Seigal, A., \& Skuse, D. (2012). Sex differences in autism spectrum disorder: Evidence from a large sample of children and adolescents. Journal of Autism and Developmental Disorders, 42, 1304-1313. doi:10.1007/s10803-011-1356-0

Neil, L., Olsson, N. C., \& Pellicano, E. (2016). The relationship between intolerance of uncertainty, sensory sensitivities and anxiety in autistic and typically developing children. Journal of Autism and Developmental Disorders, 46, 1962-1973. doi: $10.1007 / \mathrm{s} 10803-016-2721-9$

Ozsivadjian, A., Knott, F., \& Magiati, I. (2012). Parent and child perspectives on the nature of anxiety in children and young people with autism spectrum disorders: A focus group study. Autism, 16, 107-121. doi: 10.1177/1362361311431703

QSR. (2015). NVivo for Mac Version 11 [Computer software]. Burlington, MA: QSR International.

Robertson, A., Stanfield, A., Watt, J., Barry, F., Day, M., Cormack, M., \& Melville, C. (2018). The experience and impact of anxiety in autistic adults: A thematic analysis. Research in Autism Spectrum Disorders, 46, 8-18. doi: 10.1016/j.rasd.2017.11.006 
Rodgers, J., Wigham, S., McConachie, H., Freeston, M., Honey, E., \& Parr, J. R. (2016). Development of the anxiety scale for children with autism spectrum disorder (ASCASD). Autism Research, 9, 1205-1215. doi:10.1002/aur.1603

Rodgers, J., Wigham, S., McConachie, H., Freeston, M. H., Honey, E., \& Parr, J. R. (n.d.). Anxiety Scale for Children - Autism Spectrum Disorder (ASC-ASD): Guidelines for use. Newcastle, UK: Newcastle University.

Saggers, B., Klug, D., Harper-Hill, K., Costley, D., Clark, T., Bruck, S., . . Carrington, S. (2016). Australian autism educational needs analysis - What are the needs of schools, parents and students on the autism spectrum? Brisbane: Cooperative Research Centre for Living with Autism.

Shephard, E., Bedford, R., Milosavlkevic, B., Gliga, T., Jones, E., Pickles, A., . . BASIS Team (2018). Early developmental pathways to childhood symptoms of attentiondeficit hyperactivity disorder, anxiety and autism spectrum disorder. Journal of Child Psychology and Psychiatry, Advance online publication. doi:10.1111/jcpp.12947

Simpson, K., Keen, D., Adams, D., Alston-Knox, C., \& Roberts, J. (2018). Participation of children on the autism spectrum in home, school, and community. Child: Care, Health and Development, 44, 99-107. doi: 10.1111/cch.12483

South, M., \& Rodgers, J. (2017). Sensory, emotional and cognitive contributions to anxiety in autism spectrum disorders. Frontiers in Human Neuroscience, 11. 20. doi:10.3389/fnhum.2017.00020

Stanger, C., \& Lewis, M. (1993). Agreement among parents, teachers, and children on internalising and externalising behaviour problems. Journal of Clinical Child Psychology, 22, 107-115. 
Uljarevic, M., Lane, A. E., Kelly, A., \& Leekham, S. R. (2016). Sensory subtypes and anxiety in older children and adolescents with autism spectrum disorders. Autism Research, 9, doi:10.1002/aur.1602

van Steensel, F., Bögels, S. M., \& Perrin, S. (2011). Anxiety disorders in children and adolescents with autistic spectrum disorders: A meta-analysis. Clinical Child and Family Psychology Review, 14, 302. doi:10.1007/s10567-011-0097-0

Vasa, R. A., Kalb, L., Mazurek, M., Kanne, S., Freedman, B., Keefer, A., . . Murray, D. (2013). Age-related differences in the prevalence and correlates of anxiety in youth with autism spectrum disorders. Research in Autism Spectrum Disorders, 7, 13581369. doi:10.1016/j.rasd.2013.07.005

White, S. W., Oswald, D., Ollendick, T., \& Scahill, L. (2009). Anxiety in children and adolescents with autism spectrum disorders. Clinical Psychology Review, 29, 216229. doi:10.1016/j.cpr.2009.01.003

Wigham, S., Rodgers, J., South, M., McConachie, H., \& Freeston, M. (2015). The interplay between sensory processing abnormalities, intolerance of uncertainty, anxiety and restricted and repetitive behaviours in autism spectrum disorder. Journal of Autism and Developmental Disorders, 45, 943-952. doi:10.1007/s10803-014-2248-x

Wood, J. J., \& Gadow, K. D. (2010). Exploring the nature and function of anxiety in youth with autism spectrum disorders. Clinical Psychology: Science and Practice, 17, 281292. 
Table 1.

Participant Demographic Information

\begin{tabular}{|c|c|c|c|c|c|c|c|c|c|}
\hline \multicolumn{5}{|c|}{ Parent } & \multicolumn{5}{|c|}{ Child } \\
\hline Name & Relationship & Age range (years) & Highest education & Marital status & Name & Age (years) & Gender & DBC-ASA $^{\mathrm{a}}$ & ASC-ASD-P total score \\
\hline Paula & Mother & $31-40$ & Tertiary & Separated & Mia & 6 & Female & 27 & 49 \\
\hline Vanessa & Mother & $31-40$ & Tertiary & Married - & & 6 & Male & & \\
\hline Steve & Father & $31-40$ & Not provided & Married & Harrison & & & 24 & 24 \\
\hline Deanne & Mother & $31-40$ & Tertiary & Divorced & Rebecca & 8 & Female & 23 & 35 \\
\hline 1 & 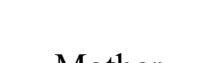 & $41=0$ & $T \cdot T_{0}$ & $\pi_{0} \cdot$ & Kahil & 8 & Male & 29 & 43 \\
\hline Amma & IVIOUIII & $41-50$ & 1етіа丿у & ivaliteu & Amelia & 8 & Female & 25 & 38 \\
\hline Tess & Mother & $41-50$ & Tertiary & Married & Georgia & 7 & Female & 24 & 31 \\
\hline Zita & Mother & $41-50$ & Secondary & De facto & Noah & 8 & Male & 49 & 47 \\
\hline Jessica & Mother & $41-50$ & Tertiary & Married & Layla & 5 & Female & 28 & 36 \\
\hline Kate & Mother & $41-50$ & Tertiary & Married & Blake & 6 & Male & 29 & 36 \\
\hline Raelene & Mother & $41-50$ & Tertiary & Single & Max & 5 & Male & 25 & 35 \\
\hline
\end{tabular}

Note. ${ }^{\text {a }}$ DBC-ASA: Developmental Behaviour Checklist-Autism Screening Algorithm was developed from the Developmental Behaviour Checklist (Einfeld \& Tonge, 2002) to measure autism characteristics. A cut-off of 17 suggests the presence of autism characteristics (Brereton et al., 2002) with higher scores indicating greater autism symptom severity.

${ }^{b}$ ASC-ASD-P: Anxiety Scale for Children with Autism Spectrum Disorder - Parent form (Rodgers et al., 2016). A total score of 24 has been identified as measuring elevated levels of anxiety (Rodgers et al., n.d.). Higher ASC-ASD-P scores indicate greater levels of anxiety. 
Parent's identification of anxiety in their child

Looking back, parents can identify early signs of their child's anxiety

Detecting anxiety may be difficult

\section{Differentiating between} anxiety and other behaviours is complex
Parental perception of the presentation and triggers of the child's anxiety across home and school

Children's anxiety about school can sometimes present at home

Anxiety can be triggered by sensory challenges.

Academic performance can be associated with anxiety

The school context can also present with social challenges across any setting can trigger anxiety

\section{Supports and Strategies}

Supporting their child with autism and anxiety is multifaceted

Teacher support can be related to understanding the individual child's anxiety

Figure 1. Overview of identified themes 